\title{
Naphthacenodithiophene Based Polymers-New Members of the Acenodithiophene Family Exhibiting High Mobility and Power Conversion Efficiency
}

\author{
Astrid-Caroline Knall,* Raja Shahid Ashraf, Mark Nikolka, Christian B. Nielsen, \\ Balaji Purushothaman, Aditya Sadhanala, Michael Hurhangee, Katharina Broch, \\ David J. Harkin, Jiři Novák, Marios Neophytou, Pascal Hayoz, Henning Sirringhaus, \\ and Iain McCulloch
}

Wide-bandgap conjugated polymers with a linear naphthacenodithiophene (NDT) donor unit are herein reported along with their performance in both transistor and solar cell devices. The monomer is synthesized starting from 2,6-dihydroxynaphthalene with a double Fries rearrangement as the key step. By copolymerization with 2,1,3-benzothiadiazole (BT) via a palladium-catalyzed Suzuki coupling reaction, NDT-BT co-polymers with high molecular weights and narrow polydispersities are afforded. These novel wide-bandgap polymers are evaluated as the semiconducting polymer in both organic field effect transistor and organic photovoltaic applications. The synthesized polymers reveal an optical bandgap in the range of $1.8 \mathrm{eV}$ with an electron affinity of $3.6 \mathrm{eV}$ which provides sufficient energy offset for electron transfer to $P C_{70} B M$ acceptors. In organic field effect transistors, the synthesized polymers demonstrate high hole mobilities of around $0.4 \mathrm{~cm}^{2} \mathrm{~V}^{-1} \mathrm{~s}^{-1}$. By using a blend of NDT-BT with $\mathrm{PC}_{70} \mathrm{BM}$ as absorber layer in organic bulk heterojunction solar cells, power conversion efficiencies of $7.5 \%$ are obtained. This value is among the highest obtained for polymers with a wider bandgap (larger than $1.7 \mathrm{eV}$ ), making this polymer also interesting for application in tandem or multijunction solar cells.

\section{Introduction}

Conjugated donor-acceptor copolymers occupy an increasingly important role in the field of organic electronics. ${ }^{[1]}$ In particular, the increased performance of organic solar cells ${ }^{[2-4]}$ can be attributed to a large extent to the improved properties of the donor polymers, ${ }^{[5]}$ which can be synthetically tailored to meet optical and electronic requirements, along with optimal solution-based processability, allowing cost-efficient device fabrication.

Recently, wide-bandgap polymers (with an $E_{\mathrm{g}}$ of over $\left.1.7 \mathrm{eV}\right)^{[6]}$ have become a major focus of OPV (organic photovoltaics) research, since they can be used in the front cell of a tandem or multijunction solar cell device to enhance the efficiency limitations of single junction devices. Power conversion efficiencies
Dr. A.-C. Knall, Dr. R. S. Ashraf, Dr. C. B. Nielsen,

Dr. B. Purushothaman, M. Hurhangee, Prof. I. McCulloch

Department of Chemistry and Centre for Plastic Electronics

Imperial College London

London SW7 2AZ, UK

E-mail: a.knall@tugraz.at

Dr. A.-C. Knall

Institute for Chemistry and Technology of Materials (ICTM)

NAWI Graz

Graz University of Technology

Stremayrgasse 9, 8010 Graz, Austria

Dr. M. Nikolka, Dr. A. Sadhanala, Dr. K. Broch, D. J. Harkin, Prof. H. Sirringhaus

Cavendish Laboratory

University of Cambridge

Cambridge CB3 OHE, UK

Dr. C. B. Nielsen

Materials Research Institute and School

of Biological and Chemical Sciences

Queen Mary University of London

Mile End Road, London E1 4NS, UK

DOI: 10.1002/adfm.201602285
Dr. J. Novák

CEITEC MU

Masaryk University and Department

of Condensed Matter Physics

Masaryk University

Kotlářská 2, 61137 Brno, Czech Republic

Dr. M. Neophytou, Prof. I. McCulloch

King Abdullah University of Science

and Technology (KAUST)

SPERC

Thuwal 23955-6900, Saudi Arabia

Dr. P. Hayoz

BASF Schweiz AC

GMV/BE, R-1059.5.09

Mattenstrasse, 4058 Basel, Switzerland

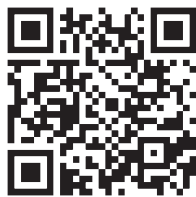

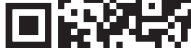


(PCEs) of up to $11.4 \%$ have been already realized, based on the multijunction concept and further improvements can be expected based on theoretical considerations which predict efficiencies of up to $20 \%$. $^{[7,8]}$

An ideal wide-bandgap polymer for tandem solar cells should convert shorter wavelength light with high conversion efficiencies to complement the low-bandgap material in the rear cell and deliver a high $V_{\mathrm{OC}}$ (open-circuit voltage) to contribute to the multijunction device's overall voltage. ${ }^{[9]}$

The cell $V_{\mathrm{OC}}$ can be increased through a decrease of the highest occupied molecular orbital (HOMO) energy level of the electron donating polymer, and consequently widebandgap polymers typically can be used to achieve a high $V_{\text {OC. }}{ }^{[6]}$ Alternatively, raising the lowest unoccupied molecular orbital of the electron acceptor has been used to increase the efficiency of devices utilizing poly-3-hexylthiophene as a classic wide-bandgap polymer whereas creating new donoracceptor copolymers with better suited HOMO levels has led to record efficiencies of wide-bandgap materials up to 9.7\%. ${ }^{[10,11]}$

Donor-acceptor copolymers have previously been demonstrated to show both high charge carrier mobilities as well as excellent PCEs. ${ }^{[5]}$ Amongst the numerous available building blocks for the synthesis of such polymers, acenodithiophenes have proven to be excellent electron-rich repeating units. ${ }^{[12]}$ These large thiophene-flanked fully aromatic planar systems consisting of two or more fused homo- or heterocyclic aromatic rings promote low energetic disorder, short intermolecular interactions, and improved charge transport. In addition, record PCEs have been achieved using building blocks from the acenodithiophene family with extended aromatic cores.

In particular, indacenodithiophene (IDT) ${ }^{[13,14]}$ has emerged as one of the most successful polymer backbone design concepts to achieve high mobility in organic field-effect transistor (OFET) devices. ${ }^{[15-18]}$ The high mobility in IDT copolymers is currently understood to be a consequence of backbone co-planarity and rigidity, resulting in a low energetic disorder, leading to charge transport taking place mainly along the polymer backbone and a limited amount of charge hopping between chains. ${ }^{[14-17]}$ In addition to this backbone rigidity, alkyl chains can be easily attached and varied, having both a profound effect on performance, but also dramatically increasing solubility, thus facilitating dissolution in nonchlorinated solvents. ${ }^{[19]}$ Although the transport properties of this polymer class are outstanding, solar cell device performance has remained modest, with less than 7\% PCE achieved.[20]
In order to simultaneously widen the bandgap and lower the HOMO energy level, the central phenyl unit of IDT was replaced with a naphthyl unit. The main effect of this design modification is that there are less thiophene rings per unit length along the backbone, thus lowering the electron density and therefore resulting in a lower HOMO energy level. This will be expected to increase the bandgap, and provide a deeper HOMO to enable larger device $V_{\mathrm{OC}}$. Herein we demonstrate the effectiveness of this approach through synthesis of naphthacenodithiophene $\left(4,4,10,10\right.$-tetraalkyl-4,10-dihydro-naphtha-[3",2":3,4;7", $\left.6^{\prime \prime}: 3^{\prime}, 4^{\prime}\right]$ -

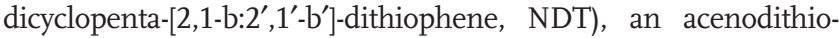
phene with a naphthalene core. From this structure, high-mobility, wide-bandgap polymers are obtained which perform well in OPV giving PCEs of $7.5 \%$ and in thin film transistor devices, exhibiting hole mobilities of up to $0.4 \mathrm{~cm}^{2} \mathrm{~V}^{-1} \mathrm{~s}^{-1}$.

\section{Results and Discussion}

\subsection{Synthesis}

Dibrominated NDT monomers with $n$-hexadecyl and 2-ethylhexyl alkyl chains were synthesized and copolymerized with 2,1,3-benzothiadiazole-4,7-bis(boronic acid pinacol ester) to afford NDT-BT copolymers (chemical structures are shown in Scheme 1). The synthesis of the NDT monomers is shown in Scheme 2 (detailed experimental procedures can be found in the Supporting Information).

BT was selected as comonomer due to its electron withdrawing nature, resulting in a hybridized molecular orbital system, as well as exhibiting an off axis dipole, which contributes to enhanced pi-stacking, close contacts and potentially high charge carrier mobilities. ${ }^{[15]}$ Due to the flanking thiophenes in NDT, unfavorable phenyl-phenyl couplings leading to large dihedral angles can be avoided, and subsequently main chain coplanarity is enhanced.

The most challenging part in this synthesis sequence was to construct a dicarboxy naphthalene scaffold with substitutions in 2, 3, 6, and 7-position due to 1, 4, 5, and 8 being the most reactive positions in the naphthalene system. In previous attempts, ortho lithiation of dihydroxynaphthalene equipped with different protecting groups resulted in ambiguous results and mixtures of multiple compounds were typically obtained. ${ }^{[21]}$

We were able to perform an anionic ortho Fries rearrangement of biscarbamate 1 leading to the key intermediate, 2,3,6,7-substituted naphthalene 2 , in good yield and purity. ${ }^{[22]}$

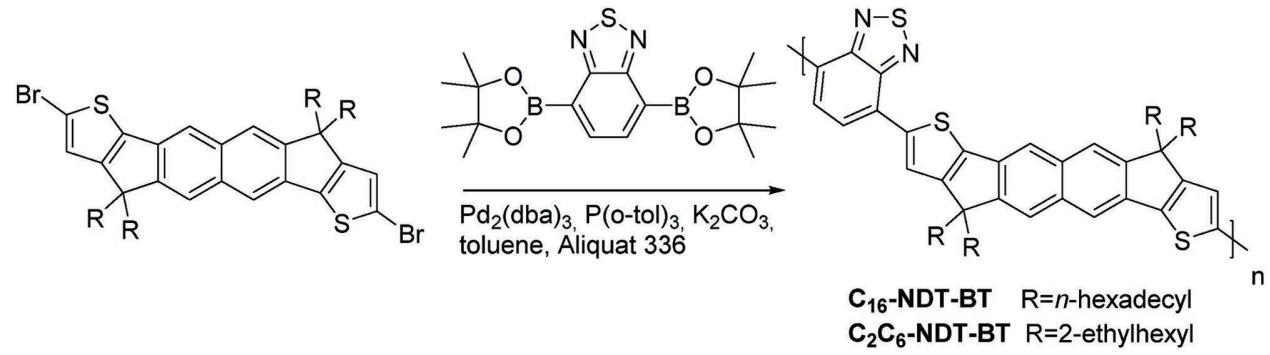

Scheme 1. Synthesis of NDT-BT polymers by palladium-catalyzed Suzuki coupling. 


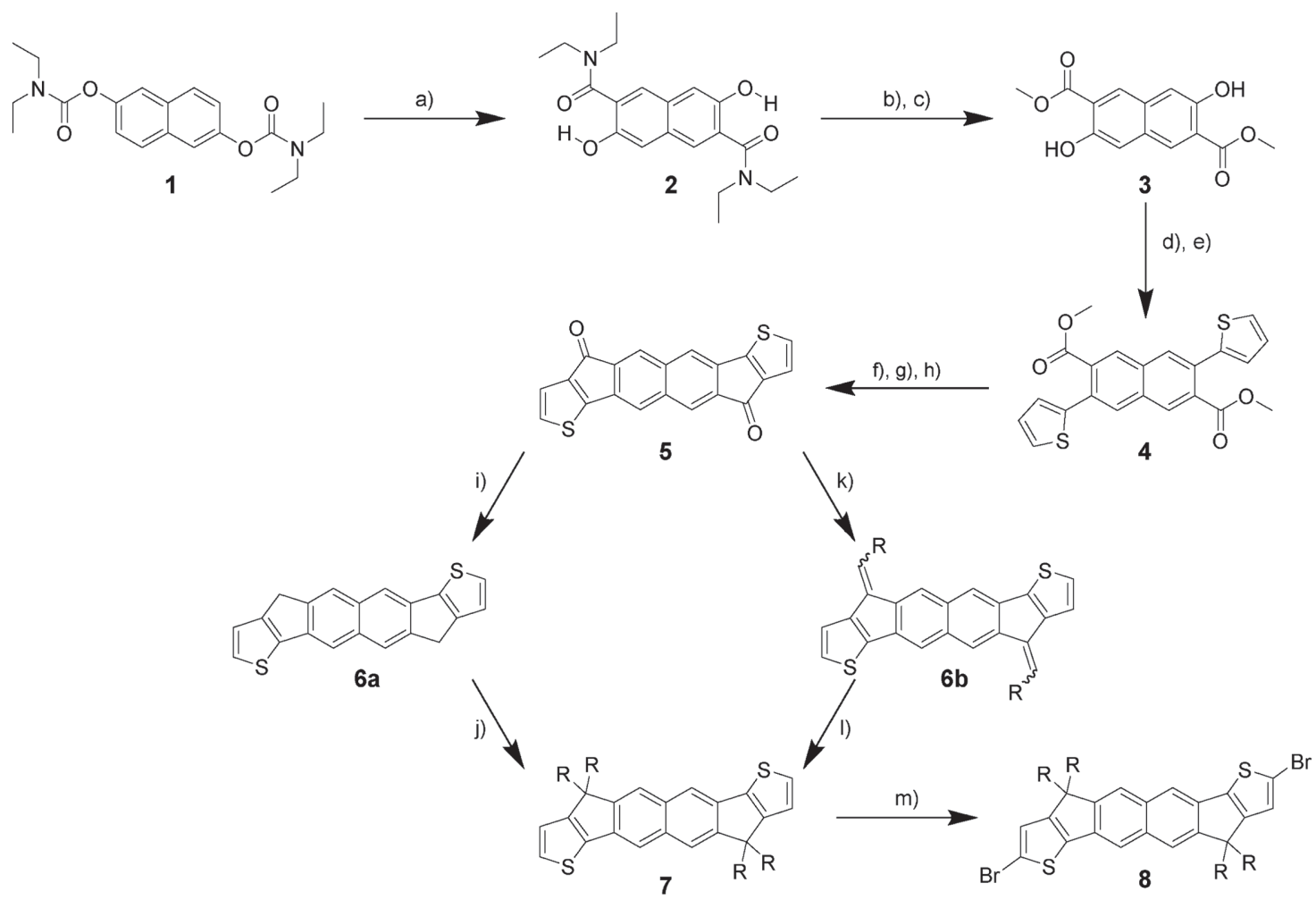

Scheme 2. Synthesis of $\mathrm{C}_{2} \mathrm{C}_{6}$-NDT (8a: $\mathrm{R}=2$-ethylhexyl) and $\mathrm{C}_{16}$-NDT (8b: $\mathrm{R}=n$-hexadecyl) dibrominated monomers. a) LDA (lithium diisopropylamide) (5 equiv.), THF (tetrahydrofuran) $-78{ }^{\circ} \mathrm{C} \rightarrow \mathrm{RT}, 49 \%$; b) TBDMSCl, $98 \%$; c) trimethyloxonium tetrafluoroborate, DCM (dichloromethane), $49 \%$; d) $\mathrm{Tf}_{2} \mathrm{O}$, pyridine, $\mathrm{DCM}, 85 \%$; e) 2-thienylzinc bromide, $\mathrm{Pd}\left(\mathrm{PPh}_{3}\right)_{4}, 82 \%$; f) $\mathrm{NaOH}, \mathrm{MeOH}, 92 \%$; g) oxalyl chloride, n.d.; h) $\mathrm{AlCl}$, $\mathrm{DCM}, 75 \%$; i) hydrazine, 77\%; j) $\mathrm{NaO}^{\mathrm{t} B u}$, 2-ethylhexyl bromide, DMSO (dimethyl sulfoxide), 10\%; k) hexadecylphosphonium bromide, $n$-BuLi, 48\%; I) 1-bromohexadecane, $\mathrm{LiAlH}_{4}, \mathrm{THF}, 15 \%$; m) NBS, chloroform, RT, $81 \%$ for $8 \mathrm{a}$ and $90 \%$ for 8 b.

The diethylamido groups were then converted into methoxyester groups using trimethyloxonium tetrafluoroborate. After triflation of the hydroxyl groups on the naphthalene scaffold 3, Negishi coupling with 2-thienylzinc bromide led to intermediate 4 which was converted in a Friedel-Crafts acylation to the desired bisketone intermediate 5 . Conversion of the amide groups was also attempted after the Negishi coupling but led to overall lower yields of 5 , most probably due to insufficient solubility of the dithienyl amide in dichloromethane or acetonitrile. Indeed, a solubilizing tert-butyldimethylsilyl (TBDMS) group had to be attached to 2 to facilitate this reaction in satisfactory yield. The TBDMS group was cleaved during the workup of 3 .

Previously, we have identified the side chains of IDT copolymers to profoundly impact both the solubility and thin film morphology which in turn influences the electronic properties. ${ }^{[19]}$ While short, branched alkyl chains are preferred in OPV applications, as this design often promotes optimal phase separation, and has been shown in some cases to help enriching fullerene molecule density close to the electron withdrawing unit of the donor, long, linear side chains were observed to enhance the polymer order and subsequent mobility in OFETs. ${ }^{[23]}$ Therefore, for comparison, 2-ethylhexyl- and $n$-hexadecyl substituted NDT derivatives 7 were both synthesized. From the diketone 5, $\mathrm{C}_{2} \mathrm{C}_{6}$-NDT (7a) could be prepared in close analogy to $\mathrm{C}_{2} \mathrm{C}_{6}$ IDT employing a Wolff-Kishner reduction to yield $\mathbf{6 a}$ which was then alkylated with 2-ethylhexyl bromide in dimethyl sulfoxide.
For the $\mathrm{C}_{16}$-substituted analogue $7 \mathbf{b}$, a Wittig reaction ${ }^{[24]}$ followed by reductive alkylation had to be pursued to obtain the product in desirable amounts. Overall, rather low yields were achieved in the final alkylation steps which are in accordance with our experience of alkylating the corresponding IDT analogues. ${ }^{[25]}$ Bromination of $7 \mathbf{a}$ and $\mathbf{7 b}$ was achieved by using $\mathrm{N}$-bromosuccinimide in chloroform in good yield and purity. Notably, applying the same conditions as for IDT (using dimethylformamide as a cosolvent) ${ }^{[16]}$ resulted in overbromination.

The dibrominated NDT monomers $8 \mathrm{a}$ and $8 \mathrm{~b}$ were copolymerized with commercially available diborylated benzothiadiazole. Suzuki polycondensation was chosen, as it avoids the use of highly toxic trimethyltin-substituted monomers by substitution with less harmful bis(boronic esters).

All polymerizations proceeded smoothly and in good yield (polymerization data is presented in Table 1). The copolymers were purified by Soxhlet extraction with acetone, hexanes, and chloroform followed by treatment with diethylammonium dithiocarbamate to remove palladium traces. The majority of $\mathrm{C}_{16}$-NDT-BT and $\mathrm{C}_{2} \mathrm{C}_{6}$-NDT-BT dissolved in the chloroform fraction. Generally, the solubility of the NDT copolymers in common organic solvents such as chloroform or chlorobenzene is good. $\mathrm{C}_{16}$-NDT-BT and $\mathrm{C}_{2} \mathrm{C}_{6}$-NDT-BT were further fractionated by preparative gel permeation chromatography (GPC) in chlorobenzene to retrieve high, medium and low molecular weight polymer fractions. The highest molecular 
Table 1. Molecular weights of the synthesized copolymers.

\begin{tabular}{lccc}
\hline Copolymer & $\begin{array}{c}M_{\mathrm{n}} \\
{[\mathrm{kDa}]}\end{array}$ & $\begin{array}{c}M_{\mathrm{w}} \\
{[\mathrm{kDa}]}\end{array}$ & PDI \\
\hline C $_{2} \mathrm{C}_{6}$-NDT-BT & 147 & 239 & 1.6 \\
& 74 & 133 & 1.8 \\
& 52 & 100 & 1.9 \\
C $16-$ NDT-BT & 70 & 158 & 2.3 \\
& 40 & 50 & 1.3 \\
\hline
\end{tabular}

weight fraction of both polymers was used for OPV measurements. ${ }^{[20,26]}$ The number average molecular weight $\left(M_{n}\right)$ and weight average molecular weight $\left(M_{\mathrm{w}}\right)$ of the different polymers are summarized in Table 1. All polymers exhibited a relatively low polydispersity and also higher molecular weight in comparison to the analogous IDT polymerizations.

\subsection{Optical and Morphological Properties}

The absorption spectra of the copolymers are shown in Figure 1. A distinct vibronic shoulder is visible in both $\mathrm{C}_{2} \mathrm{C}_{6}$-NDT-BT and $\mathrm{C}_{16}$-NDT-BT, indicating a certain degree of local order. This is in contrast to the analogous IDT-BT polymers ${ }^{[19]}$ where a vibronic shoulder could only be observed in the $\mathrm{C}_{16}$-analogue.

The optical bandgaps of both NDT copolymers are $1.8 \mathrm{eV}$, which is $0.1 \mathrm{eV}$ larger than for the IDT analogues, most likely due to the aforementioned reduction in electron density and subsequent lower HOMO energy level. The energy levels were also determined using cyclic voltammetry (see Figure S1, Supporting Information) and an ionization potential (IP) of $5.6 \mathrm{eV}$ was obtained in both cases. As expected, this value was observed to be slightly lower than the IP values determined via photoelectron spectroscopy in air (PESA) measurements (see Table 2).

The lower IP values compared to the IDT-BT polymer ${ }^{[15]}$ (see Table 2) are again most likely due to the more electron-deficient

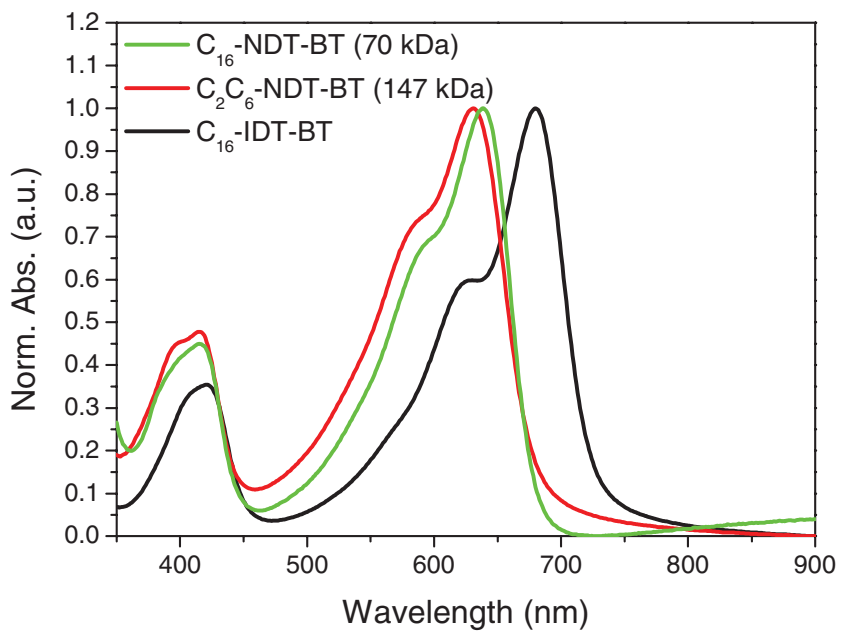

Figure 1. Thin film UV-vis absorption spectra of the polymers $C_{16}$-NDT$\mathrm{BT}, \mathrm{C}_{2} \mathrm{C}_{6}$-NDT-BT, and $\mathrm{C}_{16}$-IDT-BT measured on glass. The spectra are normalized by the absorption maximum for better comparability.
Table 2. Optical and optoelectronic properties of the synthesized copolymers.

\begin{tabular}{lccccc}
\hline Copolymer & $\begin{array}{c}\lambda_{\max } \\
{[\mathrm{nm}]}\end{array}$ & $\begin{array}{c}\left.E_{\mathrm{g}, \mathrm{opt}}{ }^{\mathrm{a}}\right) \\
{[\mathrm{eV}]}\end{array}$ & $\begin{array}{c}\mathrm{IP}_{\text {,PESA }}{ }^{\mathrm{b})} \\
{[\mathrm{eV}]}\end{array}$ & $\begin{array}{c}\left.\mathrm{IP}_{\mathrm{CV}}^{\mathrm{c}}{ }^{\mathrm{c}}\right) \\
{[\mathrm{eV}]}\end{array}$ & $\begin{array}{c}\mathrm{EA}^{\mathrm{d})} \\
{[\mathrm{eV}]}\end{array}$ \\
\hline $\mathrm{C}_{2} \mathrm{C}_{6}$-NDT-BT $(147 \mathrm{kDa})$ & 631 & 1.81 & 5.45 & 5.6 & 3.8 \\
$\mathrm{C}_{16}$-NDT-BT $(70 \mathrm{kDa})$ & 639 & 1.83 & 5.43 & 5.6 & 3.8 \\
$\mathrm{C}_{16}$-IDT-BT & 680 & 1.71 & 5.30 & & 3.6 \\
\hline
\end{tabular}

a) Estimated from the absorption onset in the UV-vis spectra; b)IP determined from PESA measurements; ${ }^{c}$ Measured via cyclic voltammetry; ${ }^{\text {d) }}$ Calculated from $\mathrm{IP}, \mathrm{cv}$ and $E_{\mathrm{g}, \mathrm{opt}}$

character of the NDT building block, which lowers the HOMO level of the donor polymer and thereby results in a potentially higher open circuit voltage in organic solar cells..$^{[6]}$

To investigate the crystallization behavior and microstructure of the NDT-BT copolymers, grazing incidence wide angle X-ray scattering (GIWAXS) measurements were performed.

GIWAXS measurements (Figure 2) on $\mathrm{C}_{16}$-NDT-BT show a Bragg-peak at $q_{\mathrm{z}}=2.8 \mathrm{~nm}^{-1}$ corresponding to an out-of-plane lattice spacing of $2.24 \mathrm{~nm}$. The polymer also shows a very weak in-plane peak at $q_{\|}=2 \mathrm{~nm}^{-1}$, which corresponds to an in-plane stacking distance of $3.14 \mathrm{~nm}$. This can be caused by regular surface corrugations or regular arrangement (longrange order) of the molecules parallel to the substrate surface. However, the long-range order parallel to the substrate surface (in-plane) is significantly less pronounced than the long-range order perpendicular to the substrate surface (out-of-plane). This is evident by the fact that the out-of-plane Bragg-peak is much sharper and more pronounced than the in-plane Braggpeak which can hardly be seen. No evidence for $\pi-\pi$-stacking was observed.

\subsection{OFET Characteristics}

Figure 3 shows representative transfer characteristics of topgate, bottom-contact OFETs based on NDT-BT co-polymers of different molecular weights with $\mathrm{C}_{2} \mathrm{C}_{6}$ and $\mathrm{C}_{16}$ side chains. For all devices, the average charge carrier mobilities (derived from three devices per polymer sample) were determined from the square root of the saturation transfer curve showing comparable performances with average hole mobilities of $0.4 \mathrm{~cm}^{2} \mathrm{~V}^{-1} \mathrm{~s}^{-1}$. Therefore, the overall performance of the NDT-BT devices shows an unusual invariance to the particular choice of side chain. Interestingly, in contrast to the polymer IDT-BT, the extracted charge carrier mobilities for all NDT-BT polymers are exhibiting strong gate-voltage dependences (Figure 3c). Since the output characteristics of the NDT-BT devices (Figure 3b) are showing a highly linear behavior at low drain voltages and low gate voltages of $V_{\mathrm{G}}=-20 \mathrm{~V}$, we cannot associate the observed gate-voltage dependence of mobility to poor charge carrier injection (full output characteristics are shown in Figure S2 in the Supporting Information). Instead, a gate voltage dependent mobility seems characteristic for the NDT-BT polymers investigated.

Comparing the performances of $\mathrm{C}_{16}$-NDT-BT with different molecular weights, we interestingly observe that an increase in 
(a)

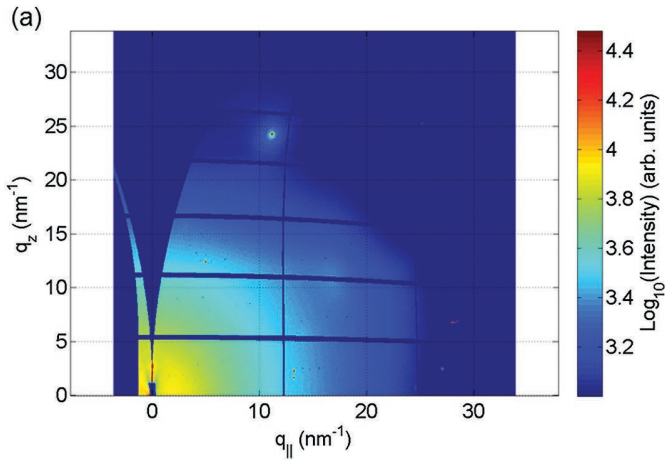

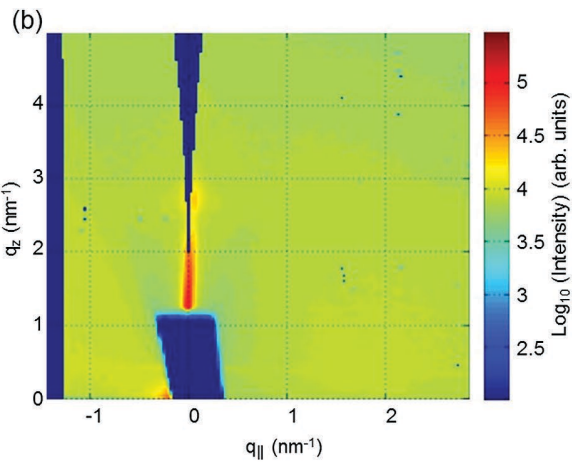

Figure 2. GIWAXS measurements of the polymer $\mathrm{C}_{16}$-NDT-BT $(70 \mathrm{kDa})$ : Image a) shows the entire range of the detector, b) shows a magnification featuring an out-of-plane Bragg-peak at $q_{\mathrm{z}}=2.8 \mathrm{~nm}^{-1}$ and a weak broad in-plane maximum centered around $q_{\|}=2 \mathrm{~nm}^{-1}$.

molecular weight actually results in a reduction of on-currents and charge carrier mobility. To investigate this observation, we performed photothermal deflection spectroscopy (PDS) on polymer films prepared from NDT-BT with different molecular weight as well as different side chains. PDS is a highly sensitive absorption measurement technique, which can be used to probe the energetic disorder in a material. The obtained data are shown in Figure 4.

The results of the PDS measurements of NDT-BT with different molecular weights and side chains are in good agreement with the data gained from the OFET measurements. Low energetic disorder was observed in all polymers, with extracted Urbach energies of $E_{\mathrm{u}}=33 \mathrm{meV}$ for $\mathrm{C}_{16}$-NDT-BT $(40 \mathrm{kDa})$, $E_{\mathrm{u}}=34 \mathrm{meV}$ for $\mathrm{C}_{2} \mathrm{C}_{6}$-NDT-BT and $E_{\mathrm{u}}=35 \mathrm{meV}$ for $\mathrm{C}_{16}$-NDTBT $(70 \mathrm{kDa})$. These values are comparable to many diketopyrrolopyrrole-based polymers, however higher than for IDT-BT $\left(E_{\mathrm{u}}=24 \mathrm{meV}\right)$ which also exhibits higher charge carrier mobilities of $1.5-2.5 \mathrm{~cm}^{2} \mathrm{~V}^{-1} \mathrm{~s}^{-1}$. ${ }^{17]}$ Additionally, the slightly higher Urbach energy as well as the increased sub-bandgap absorption between 1.0 and $1.6 \mathrm{eV}$ of the high molecular weight fraction of $\mathrm{C}_{16}$-NDTBT indicate that disorder in this polymer sample is increased, perhaps due to the higher viscosity of the longer chains, impeding cooperative motion required for long range organization. ${ }^{[27]}$
Nevertheless, overall it seems surprising that by extending the IDT-conjugated backbone into a more rigid NDT unit, the energetic disorder in NDT-BT is increased by at least $9 \mathrm{meV}$ as compared to IDT-BT. Since both torsion susceptible links of IDT-BT and NDT-BT are the same, the increased disorder is less likely to be caused by a significantly altered torsion profile and as a consequence, an increase in backbone torsion. Instead, it is likely that the higher disorder measured for the NDT-BT copolymer is caused by a change in side chain packing. In fact, due the extended NDT unit, there are less side chains per monomer unit as compared to IDT-BT which inevitably will lead to a lower side chain packing density. This could also explain, why in NDTBT, there is no significant change between the $n$-hexadecyl and 2-ethylhexyl side chains, whereas for IDT-BT, a drop in charge carrier mobility and an increase in disorder can be observed. ${ }^{[17]}$

\subsection{Photovoltaic Properties}

The performance of both NDT-BT polymers in combination with $\mathrm{PC}_{70} \mathrm{BM}$ as absorber layer in bulk heterojunction solar cells was evaluated in an inverted device architecture (glass/indium tin oxide (ITO)/ZnO/NDT-BT:PC ${ }_{70} \mathrm{BM} / \mathrm{MoO}_{3} / \mathrm{Ag}$ ). The active a)

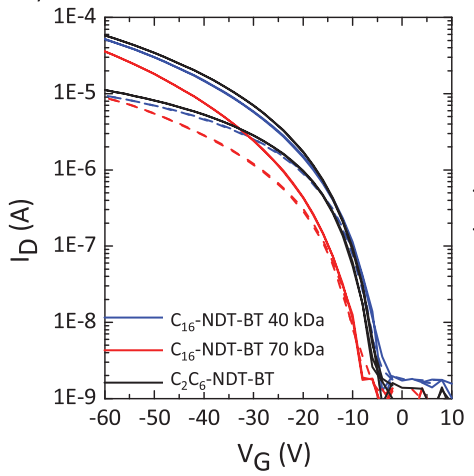

b)

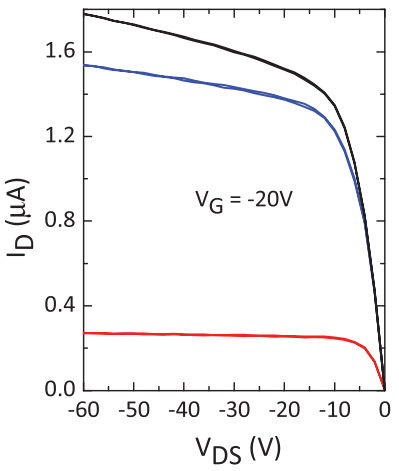

c)

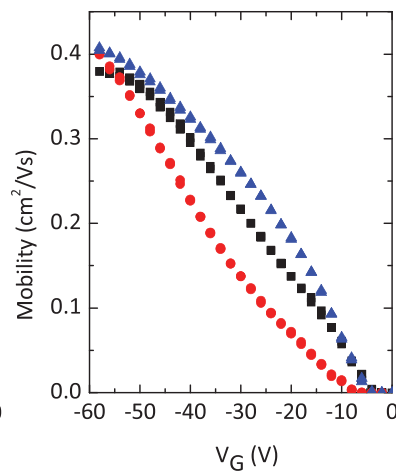

Figure 3. a) Transfer characteristics, b) output characteristics, and c) gate-voltage dependence of saturation mobility for OFET devices $(L=20 \mu \mathrm{m}$, $W=1 \mathrm{~mm}$ ) prepared with different molecular weight of $C_{16}$ and $C_{2} C_{6}$-NDT-BT. In the transfer curves (a), the dashed curves correspond to $V_{D}=-5 V$ and the solid curves to $V_{D}=-50 \mathrm{~V}$. 


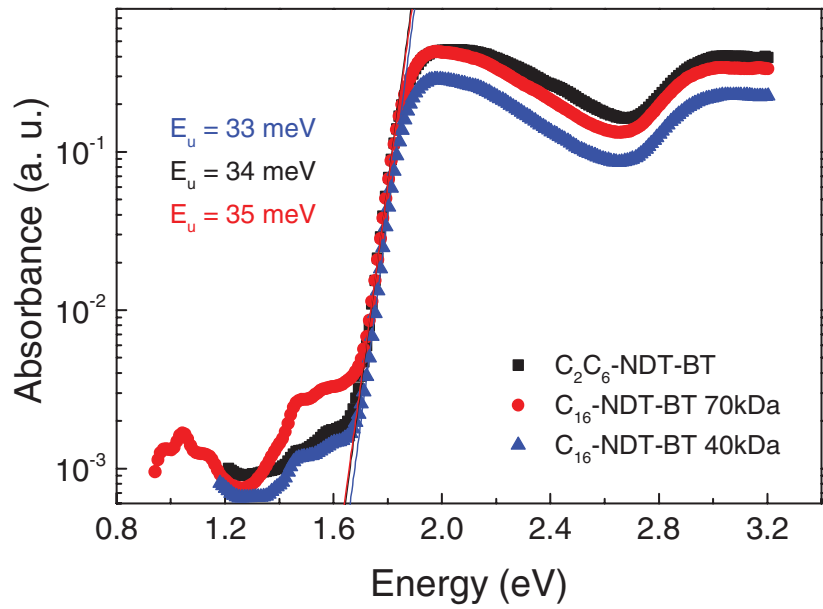

Figure 4. Absorption coefficients versus energy of $\mathrm{C}_{2} \mathrm{C}_{6}$-NDT-BT and $\mathrm{C}_{16}$-NDT-BT thin films, measured by PDS to probe the energetic disorder. The Urbach energies $E_{\mathrm{u}}$ are extracted by exponential fitting of the absorption tails in the vicinity of the bandgap.

layers were spin coated from o-dichlorobenzene using diiodooctane (DIO, $3 \% \mathrm{v} / \mathrm{v}$ ) as additive with a blend of polymer: $\mathrm{PC}_{70} \mathrm{BM}$ in a $1: 2(\mathrm{w} / \mathrm{w})$ ratio. The $J-V$ (current-voltage) curves as well as the external quantum efficiency (EQE) spectra of typical solar cells prepared with these polymers are shown in Figure 5. The characteristic solar cell parameters are summarized in Table 3.

As expected, due to deeper HOMO energy levels, both NDT-BT copolymers exhibited a larger $V_{\mathrm{OC}}$ than the analogous IDT-BT polymers, ${ }^{[20]}$ with $V_{\text {OC }}$ values of up to $0.92 \mathrm{~V}$ achieved with the $\mathrm{C}_{2} \mathrm{C}_{6}$ polymer. A small difference in $V_{\mathrm{OC}}$ was observed between the two polymers, perhaps due to interfacial recombination effects. A similar trend was observed for IDT-BT copolymers with different alkyl chains. ${ }^{[19]}$ The $\mathrm{C}_{2} \mathrm{C}_{6}$-NDT-BT:PC ${ }_{70} \mathrm{BM}$ blend shows high photocurrent values yielding a current density of $15.1 \mathrm{~mA} \mathrm{~cm}^{-2}$ and a PCE of $7.5 \%$. Although $J_{\mathrm{SC}}$ (short circuit current) and $\mathrm{FF}$ (fill factor) are comparable to the $\mathrm{C}_{2} \mathrm{C}_{6}$-IDT-BT polymer, due to higher $V_{\mathrm{OC}}$, the $\mathrm{C}_{2} \mathrm{C}_{6}$-NDT-BT polymer shows a better overall performance. This is the highest PCE reported for a polymer within the IDT family, despite the relatively low fill factor. We speculate that insufficient phase separation leads to increased nongeminate recombination resulting in a lower fill factor compared to other high efficiency polymer/fullerene blends with more pronounced phase separation. ${ }^{[28,29]}$ The EQE spectra of polymer: $\mathrm{PC}_{70} \mathrm{BM}$ blend show a broad and high response between 400 and $650 \mathrm{~nm}$. It is obvious that the main absorption band of NDT-BT contributes to the photocurrent generation and external quantum efficiencies of over 0.8 are reached for $\mathrm{C}_{2} \mathrm{C}_{6}$-NDT-BT polymer.

In comparison to the $\mathrm{C}_{2} \mathrm{C}_{6}$-NDT-BT, the photocurrent of the $\mathrm{C}_{16}$ analogue is considerably lower, with only $8.6 \mathrm{~mA} \mathrm{~cm}-2$ obtained. This is in agreement with previously published results from the IDT polymer series, where lower efficiencies have been observed for $\mathrm{C}_{16}$-IDT-BT than for $\mathrm{C}_{2} \mathrm{C}_{6}$-IDT-BT and unfavorable phase separation behavior was found to negatively influence the performance of solar cells prepared using longer, linear alkyl side chains. ${ }^{[19]}$

Atomic force microscopy (AFM) was used to investigate the surface morphologies as well as the phase separation between donor and acceptor of the NDT-BT:PC ${ }_{70} \mathrm{BM}$ blends (Figure 6). A homogeneous film is observed for each blend, and there are no distinct variations in nanoscale morphology. $\mathrm{C}_{2} \mathrm{C}_{6}$ NDT-BT:PC ${ }_{70} \mathrm{BM}$ blends exhibit slightly coarser morphologies, which is supported by the increased root-mean-square surface roughness $(1.12 \mathrm{~nm})$ compared to the $C_{16}$ analogue $(0.90 \mathrm{~nm})$. According to the phase images, domain sizes of donor and acceptor are very small. Also, in the phase images, a slightly increased phase separation is observed in the $\mathrm{C}_{2} \mathrm{C}_{6}$-NDT$\mathrm{BT}: \mathrm{PC}_{70} \mathrm{BM}$ blend.

\section{Conclusion}

New acenodithiophene monomers with a naphthalene core (NDT) and different alkyl chains have been synthesized and copolymerized with benzothiadiazole (BT) using Suzuki coupling. The resulting novel copolymers have been tested for OPV and OFET applications. A respectable charge carrier mobility of $0.4 \mathrm{~cm}^{2} \mathrm{~V}^{-1} \mathrm{~s}^{-1}$ was achieved, which, unusually, was similar for both 2-ethylhexyl and $n$-hexadecyl substituted polymers. Compared to the indacenodithiophene analogue, the absorption maximum of both NDT-BT polymers is blue-shifted and a bandgap of $1.8 \mathrm{eV}$ is observed which is $0.1 \mathrm{eV}$ larger than
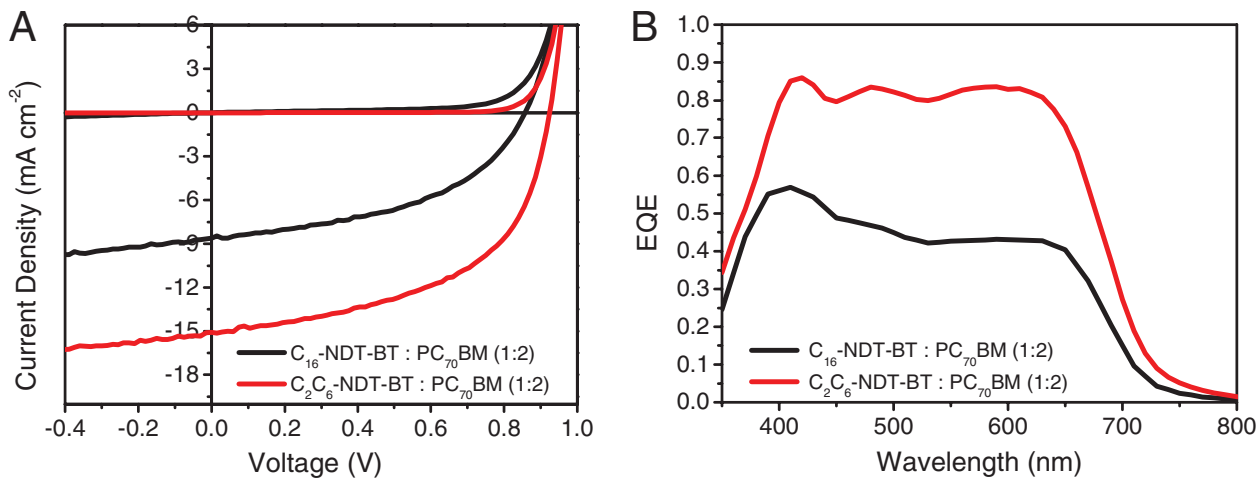

Figure 5. a) Typical $J-V$ curves of solar cells with $C_{16}$-NDT-BT $(70 \mathrm{kDa})$ : $P C_{70} B M$ and $C_{2} C_{6}$ - and $C_{2} C_{6}-N D T-B T\left(147\right.$ kDa): $P C_{70} B M$ absorber layers in inverted device architecture and b) their corresponding EQE-spectra. 
Table 3. Characteristic parameters of the prepared solar cells.

\begin{tabular}{lcccc}
\hline Polymer & $\begin{array}{c}J_{S C} \\
{\left[\mathrm{~mA} \mathrm{~cm}^{-2}\right]}\end{array}$ & $\begin{array}{c}V_{O C} \\
{[\mathrm{~V}]}\end{array}$ & $F F$ & $\begin{array}{c}\text { PCE } \\
{[\%]}\end{array}$ \\
\hline C $_{16}$-NDT-BT & $8.4 \pm 0.2(8.6)^{\mathrm{a})}$ & $0.85 \pm 0.01(0.86)^{\mathrm{a})}$ & $0.47 \pm 0.02(0.47)^{\mathrm{a})}$ & $3.4 \pm 0.1(3.5)^{\mathrm{a})}$ \\
$\mathrm{C}_{2} \mathrm{C}_{6}$-NDT-BT & $15.0 \pm 0.3(15.1)^{\mathrm{a})}$ & $0.92 \pm 0.01(0.92)^{\mathrm{a})}$ & $0.53 \pm 0.01(0.54)^{\mathrm{a})}$ & $7.4 \pm 0.1(7.5)^{\mathrm{a})}$ \\
$\mathrm{C}_{2} \mathrm{C}_{6}$-IDT-BT $^{[20]}$ & 14.5 & 0.80 & 0.56 & 6.5 \\
\hline
\end{tabular}

a) Parenthesis values are for best devices, average values derived from 5 to 6 devices.

the IDT analogue. 2-Ethylhexyl substituted NDT-BT exhibits a PCE of $7.5 \%$ which is the highest reported so far for an indacenodithiophene-type donor polymer. This can be mainly attributed to an increase in open circuit voltage to $0.92 \mathrm{~V}$ caused by lowering the HOMO level compared to IDT-BT. Notably, a high photocurrent was observed over the whole absorption range of the polymer $(450-700 \mathrm{~nm})$ as shown by EQE measurements. This ability to efficiently convert short wavelength light together with high charge carrier mobility and a high $V_{\mathrm{OC}}$ makes this new addition to the IDT family of polymers a promising candidate for application in tandem solar cells.

\section{Experimental Section}

Materials and Methods: All chemicals were purchased from commercial suppliers and used as received unless otherwise specified. Column chromatography was carried out with silica gel for flash chromatography from VWR. ${ }^{1} \mathrm{H}$ and ${ }^{13} \mathrm{C}$ NMR spectra were recorded on a Bruker Model 400 spectrometer. A custom-build Shimadzu SEC system was used to fractionate the polymers with chlorobenzene at $80^{\circ} \mathrm{C}$ as the eluent. The system comprised a DGU-20A3 degasser, an

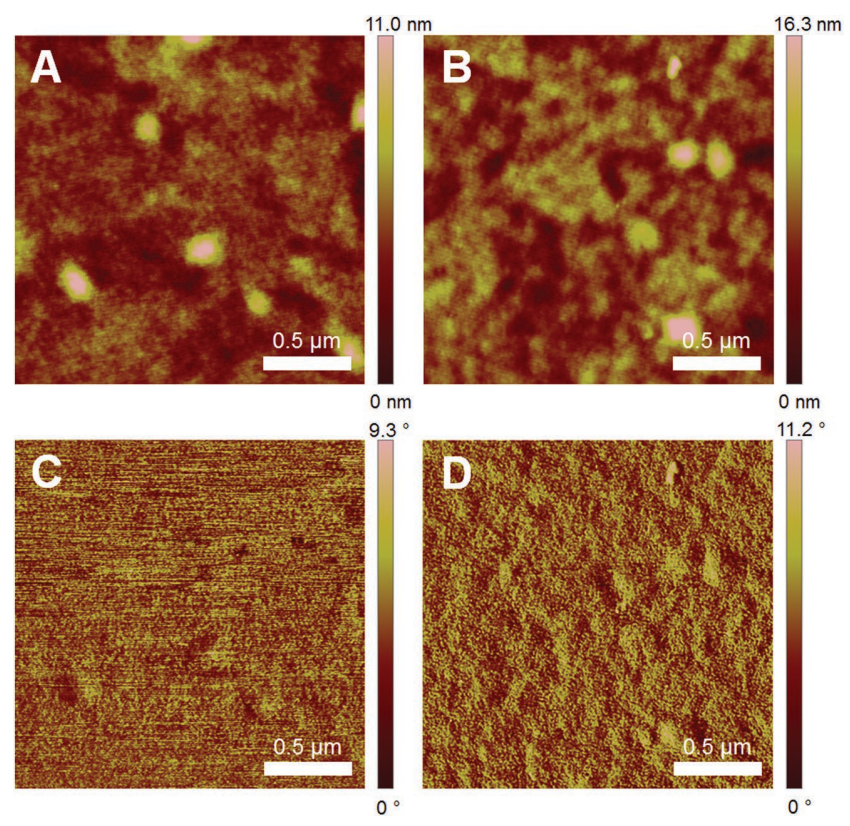

Figure 6. AFM topography $(a, b)$ and phase $(c, d)$ images $(2 \times 2 \mu \mathrm{m})$ acquired in tapping mode of $(a, c) C_{16}$-NDT-BT:PC ${ }_{70} B M$ and $(b, d) \quad C_{2} C_{6}$-NDT$\mathrm{BT}: \mathrm{P}_{70} \mathrm{CBM}$ blend films as used for solar cell preparation (see Supporting Information for a height histogram analysis).
LC-20A pump, a CTO-20A column oven, an Agilent PLgel $10 \mu \mathrm{m}$ MIXED-D column and a SPD-20A UV detector. Number-average $\left(M_{n}\right)$ and weightaverage $\left(M_{w}\right)$ molecular weights were determined with an Agilent Technologies 1200 series GPC in chlorobenzene at $80^{\circ} \mathrm{C}$, using two $\mathrm{PL}$ mixed $B$ columns in series, and calibrated against narrow weight-average dispersity $\left(D_{\mathrm{W}}<1.10\right)$ polystyrene standards. UV-vis absorption spectra were recorded on a UV-1601 Shimadzu UV-vis spectrometer. Cyclic voltammetry was performed with a standard three-electrode setup with a Pt-mesh counter electrode and an $\mathrm{Ag} / \mathrm{Ag}^{+}$reference electrode calibrated against $\mathrm{Fc} / \mathrm{Fc}^{+}$using an Autolab PGSTAT101 potentiostat. The measurements were carried out using spin cast films (from chloroform solutions, $5 \mathrm{mg} \mathrm{mL}^{-1}$ ) on ITO-coated glass substrates with $0.1 \mathrm{M}$ tetrabutylammonium hexafluorophosphate in deoxygenated acetonitrile as supporting electrolyte; scan rate was $50 \mathrm{mV} \mathrm{s}^{-1}$. IP energy values were obtained using the following equation: $E_{\mathrm{IP}}=-\left(E_{\mathrm{OX}}-E_{\mathrm{Fc}+}+\right.$ 4.88) eV. PESA measurements were performed with a Riken Keiki Model AC-2 spectrometer on samples prepared on glass substrates. AFM was carried out using a Dimension 3100 atomic force microscope in close contact (tapping) mode. The GIWAXS measurements were performed at beamline 107 Diamond Light Source, Didcot, UK using a Pilatus 1M detector and a beam energy of $12.5 \mathrm{keV}$. NDT-BT films were deposited on silicon substrates followed by thermal annealing at $100{ }^{\circ} \mathrm{C}$ for $1 \mathrm{~h}$ The sample was placed in a protective atmosphere to reduce beam damage and air scattering.

Polymer Synthesis: $\quad C_{16}$-NDT-BT-2,8-Dibromo-4,4,10,10-tetrakis(hexadecyl)-4,10-dihydro-naphtho[3", $\left.2^{\prime \prime}: 3,4 ; 7^{\prime \prime}, 6^{\prime \prime}: 3^{\prime}, 4^{\prime}\right] \quad$ dicyclopenta[2,1b: $2^{\prime}, 1^{\prime}$-b']-dithiophene (8b, $\left.85.63 \mathrm{mg}, 0.06241 \mathrm{mmol}\right)$ and 4,7-bis (4,4,5,5-tetramethyl-1,3,2-dioxaborolan-2-yl)benzo[c][1,2,5]thiadiazole (24.23 $\mathrm{mg}, 0.06243 \mathrm{mmol}$ ) were placed in a $20 \mathrm{~mL}$ microwave vial. $\mathrm{Pd}_{2}(\mathrm{dba})_{3}\left(3.01 \mathrm{mg}, 2.9 \times 10^{-3} \mathrm{mmol}\right),(0 \text {-tol })_{3} \mathrm{P}(4.01 \mathrm{mg}, 0.0132 \mathrm{mmol})$, Aliquat 336 (1 drop), and toluene $(5 \mathrm{~mL})$ were added. This solution was degassed with argon for 30 min. Then, degassed $\mathrm{Na}_{2} \mathrm{CO}_{3}$ solution $(1 \mathrm{M}, 1 \mathrm{~mL}$ ) was added and the resulting mixture was degassed for another $10 \mathrm{~min}$. Then, the vial was sealed and heated at $120^{\circ} \mathrm{C}$ for $48 \mathrm{~h}$

To end-cap the polymer chains, $100 \mu \mathrm{L}$ bromobenzene were added via syringe and the refluxing was continued for $2 \mathrm{~h}$. Then, phenylboronic acid $(100 \mathrm{mg})$ was added and the reaction mixture was refluxed overnight. The resulting blue solution was precipitated into methanol and the precipitated polymer was recovered by filtration directly into an extraction thimble. Soxhlet extractions were performed with acetone, hexanes, and chloroform. The majority of the polymer was dissolved in the hexanes fraction. The hexanes and chloroform fractions were combined and redissolved in chloroform. This solution was treated with diethylammonium dithiocarbamate to remove palladium salts after which the organic phase was extracted with water three times, dried over magnesium sulfate and concentrated to about $2 \mathrm{~mL}$. This concentrated solution was precipitated into methanol and this precipitation was repeated twice. $67 \mathrm{mg}$ (79\%) of a deep blue metallic solid with purple reflection were obtained.

${ }^{1} \mathrm{H}$ NMR $\left(400 \mathrm{MHz}, \mathrm{CDCl}_{3}, \delta\right): 8.2(\mathrm{br} \mathrm{s}, 2 \mathrm{H}), 8.0$ (br s, $\left.1 \mathrm{H}\right)$, 7.9 (br s, 1H), 7.8 (br s, 2H), 2.2-2.0 (br m, 8H), 1.3-1.1 (br m, 112H), $0.89(\mathrm{t}, 12 \mathrm{H})$.

$\mathrm{C}_{2} \mathrm{C}_{6}$-NDT-BT-2,8-Dibromo-4,4,10,10-tetrakis (2-ethylhexyl)-4,10-dihydro-

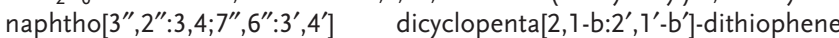
(8a, $144.82 \mathrm{mg}, 0.1569 \mathrm{mmol})$ and 4,7-bis $(4,4,5,5$-tetramethyl-1,3,2dioxaborolane-2-yl)benzo[c][1,2,5]thiadiazole $(60.86 \mathrm{mg}, 0.1568 \mathrm{mmol})$ were placed in a $20 \mathrm{~mL}$ microwave vial. $\mathrm{Pd}_{2}(\mathrm{dba})_{3}(8.11 \mathrm{mg}$, $\left.7.8 \times 10^{-3} \mathrm{mmol}\right),(o \text {-tol })_{3} \mathrm{P}(7.32 \mathrm{mg}, 0.0238 \mathrm{mmol})$, Aliquat 336 (1 drop), and toluene $(5 \mathrm{~mL})$ were added. This solution was degassed with argon for $30 \mathrm{~min}$. Then, degassed $\mathrm{Na}_{2} \mathrm{CO}_{3}$ solution $(1 \mathrm{M}, 1 \mathrm{~mL})$ was added and the resulting mixture was degassed for another $10 \mathrm{~min}$. Then, the vial was sealed and heated at $120^{\circ} \mathrm{C}$ for $48 \mathrm{~h}$.

To end-cap the polymer chains, $100 \mu \mathrm{L}$ bromobenzene were added via syringe and the reaction mixture was continued to reflux for $2 \mathrm{~h}$ 
Then, phenylboronic acid $(100 \mathrm{mg})$ was added and the reaction mixture was refluxed overnight. The resulting blue solution was precipitated into methanol and the precipitated polymer was recovered by filtration directly into an extraction thimble. Soxhlet extractions were performed with acetone, hexanes, and chloroform. The majority of the polymer was dissolved in the chloroform fraction. This solution was treated with diethylammonium dithiocarbamate to remove palladium salts after which the organic phase was extracted with water three times, dried over magnesium sulfate and concentrated to about $2 \mathrm{~mL}$. This concentrated solution was precipitated into methanol and this precipitation was repeated twice. $126 \mathrm{mg}$ ( $90 \%$ yield) of a blue solid with purple reflection were obtained.

${ }^{1} \mathrm{H} \mathrm{NMR}\left(400 \mathrm{MHz}, \mathrm{CDCl}_{3}, \delta\right): 8.2$ (br s, $\left.2 \mathrm{H}\right), 8.0$ (br s, $\left.1 \mathrm{H}\right), 7.9$ (br s, $1 \mathrm{H}), 7.8$ (br s, $2 \mathrm{H}), 2.2-2.0$ (br m, 8H), 1.1-0.46 (br m, 60H).

Device Fabrication and Characterization: Organic bottom-contact top-gate field effect transistors were fabricated on glass substrates with photo-lithographically patterned $\mathrm{Ti} / \mathrm{Au}(10 / 30 \mathrm{~nm})$ electrodes. For patterning the electrodes a double layer lift-off process in $\mathrm{N}$-methyl-2pyrrolidone was used. NDT-BT films were deposited by spin coating from a $10 \mathrm{mg} \mathrm{mL}^{-1}$ dichlorobenzene (DCB) solution. On top of the as-cast films a $500 \mathrm{~nm}$ thick CYTOP dielectric layer was subsequently deposited by spin coating.

Devices were finished off by evaporating a $25 \mathrm{~nm}$ thick gold top gate through a shadow mask. After fabrication transistor transfer characteristics were recorded with an Agilent 4155B Semiconductor Parameter Analyzer. To obtain good electron transport as well as to guarantee batch-to-batch reproducibility, all fabrication steps and the electrical measurement were performed in a $\mathrm{N}_{2}$ glove box.

Bulk heterojunction solar cells were fabricated with an inverted architecture (glass/ITO/ZnO/Polymer: $\mathrm{PC}_{70} \mathrm{BM}(1: 2) / \mathrm{MoO}_{3} / \mathrm{Ag}$ ). Glass substrates were used with prepatterned ITO. These were cleaned by sonication in detergent, deionized water, acetone, and isopropanol, followed by oxygen plasma treatment. $\mathrm{ZnO}$ layers were deposited by spin coating a zinc acetate dihydrate precursor solution $(60 \mu \mathrm{L}$ monoethanolamine in $2 \mathrm{~mL}$ 2-methoxyethanol) followed by annealing at $150{ }^{\circ} \mathrm{C}$ for $10-15 \mathrm{~min}$, giving layers of $30 \mathrm{~nm}$. The polymer: $\mathrm{PC} \mathrm{C}_{70} \mathrm{BM}(1: 2)$ active layers were deposited from $30 \mathrm{mg} \mathrm{mL}^{-1}$ solutions in $0-\mathrm{DCB}$. DIO was used as additive $(3 \% \mathrm{v} / \mathrm{v})$ and spin coating at $1500 \mathrm{rpm}$ was done in a glove box. $\mathrm{MoO}_{3}(10 \mathrm{~nm})$ and $\mathrm{Ag}(100 \mathrm{~nm})$ layers were deposited by evaporation through a shadow mask yielding active areas of $0.045 \mathrm{~cm}^{2}$ in each device. Current density-voltage $(J-V)$ characteristics were measured using a Xenon lamp at AM1.5 solar illumination (Oriel Instruments) calibrated to a silicon reference cell with a Keithley 2400 source meter, correcting for spectral mismatch. Incident photon conversion efficiency was measured by a $100 \mathrm{~W}$ tungsten halogen lamp (Bentham IL1 with Bentham 605 stabilized current power supply) coupled to a monochromator with computer controlled stepper motor. The photon flux of light incident on the samples was calibrated using a UV enhanced silicon photodiode. A $590 \mathrm{~nm}$ long pass glass filter was inserted into the beam at illumination wavelengths longer than $580 \mathrm{~nm}$ to remove light from second order diffraction. Measurement duration for a given wavelength was sufficient to ensure the current had stabilized.

\section{Supporting Information}

Supporting Information is available from the Wiley Online Library or from the author.

\section{Acknowledgements}

This work was carried out with financial support from BASF. Funding is gratefully acknowledged from Austrian Science Fund (FWF): T578N19, EC FP7 Project SC2 (610115), EC FP7 Project ArtESun (604397), EPSRC EP/G037515/1, and EPSRC EP/M005143/1. The authors thank
Dr. T. Arnold, Diamond Light Source, Didcot, UK and J. Rozbořil, Masaryk University, Brno, Czech Republic for assistance with the GIWAXS-measurements. Financial support from Diamond Light Source is gratefully acknowledged. K. B. gratefully acknowledges financial support from the German Research Foundation (BR 4869/1-1). J. N. acknowledges support from the project CEITEC 2020 (grant No. LQ1601 financed by the MEYS of the Czech Republic).

Received: May 9, 2016

Revised: July 5, 2016

Published online:

[1] L. Biniek, B. C. Schroeder, C. B. Nielsen, I. McCulloch, J. Mater. Chem. 2012, 22, 14803

[2] Z. He, B. Xiao, F. Liu, H. Wu, Y. Yang, S. Xiao, C. Wang, T. P. Russell, Y. Cao, Nat. Photonics 2015, 9, 174.

[3] Y. Liu, J. Zhao, Z. Li, C. Mu, W. Ma, H. Hu, K. Jiang, H. Lin, H. Ade, H. Yan, Nat. Commun. 2014, 5, 5293

[4] L. Dou, J. You, Z. Hong, Z. Xu, G. Li, R. A. Street, Y. Yang, Adv. Mater. 2013, 25, 6642.

[5] L. Lu, T. Zheng, Q. Wu, A. M. Schneider, D. Zhao, L. Yu, Chem. Rev. 2015, 115, 12666.

[6] J. You, L. Dou, Z. Hong, G. Li, Y. Yang, Prog. Polym. Sci. 2013, 38, 1909.

[7] C.-C. Chen, W.-H. Chang, K. Yoshimura, K. Ohya, J. You, J. Gao, Z. Hong, Y. Yang, Adv. Mater. 2014, 26, 5670.

[8] N. Li, D. Baran, G. D. Spyropoulos, H. Zhang, S. Berny, M. Turbiez, T. Ameri, F. C. Krebs, C. J. Brabec, Adv. Energy Mater. 2014, 4, 1400084

[9] N. Li, C. J. Brabec, Energy Environ. Sci. 2015, 8, 2902.

[10] L. Huo, T. Liu, X. Sun, Y. Cai, A. J. Heeger, Y. Sun, Adv. Mater. 2015, 27, 2938.

[11] G. Li, X. Gong, J. Zhang, Y. Liu, S. Feng, C. Li, Z. Bo, ACS Appl. Mater. Interfaces 2016, 8, 3686.

[12] K. Takimiya, S. Shinamura, I. Osaka, E. Miyazaki, Adv. Mater. 2011, 23, 4347.

[13] I. McCulloch, R. S. Ashraf, L. Biniek, H. Bronstein, C. Combe, J. E. Donaghey, D. I. James, C. B. Nielsen, B. C. Schroeder, W. Zhang, Acc. Chem. Res. 2012, 45, 714.

[14] X. Zhang, H. Bronstein, A. J. Kronemeijer, J. Smith, Y. Kim, R. J. Kline, L. J. Richter, T. D. Anthopoulos, H. Sirringhaus, K. Song, M. Heeney, W. Zhang, I. McCulloch, D. M. DeLongchamp, Nat. Commun. 2013, 4, 2238.

[15] D. Venkateshvaran, M. Nikolka, A. Sadhanala, V. Lemaur, M. Zelazny, M. Kepa, M. Hurhangee, A. J. Kronemeijer, V. Pecunia, I. Nasrallah, I. Romanov, K. Broch, I. McCulloch, D. Emin, Y. Olivier, J. Cornil, D. Beljonne, H. Sirringhaus, Nature 2014, 515, 384.

[16] W. Zhang, J. Smith, S. E. Watkins, R. Gysel, M. McGehee, A. Salleo, J. Kirkpatrick, R. S. Ashraf, T. Anthopoulos, M. Heeney, I. McCulloch, J. Am. Chem. Soc. 2010, 132, 11437.

[17] W. Zhang, Y. Han, X. Zhu, Z. Fei, Y. Feng, N. D. Treat, H. Faber, N. Stingelin, I. McCulloch, T. D. Anthopoulos, M. Heeney, Adv. Mater. 2016, 28, 3922.

[18] S. Holliday, J. E. Donaghey, I. McCulloch, Chem. Mater. 2014, 26, 647.

[19] H. Bronstein, D. S. Leem, R. Hamilton, P. Woebkenberg, S. King, W. Zhang, R. S. Ashraf, M. Heeney, T. D. Anthopoulos, J. de Mello, I. McCulloch, Macromolecules 2011, 44, 6649.

[20] R. S. Ashraf, B. C. Schroeder, H. A. Bronstein, Z. Huang, S. Thomas, R. J. Kline, C. J. Brabec, P. Rannou, T. D. Anthopoulos, J. R. Durrant, I. McCulloch, Adv. Mater. 2013, 25, 2029.

[21] H. Houjou, T. Motoyama, S. Banno, I. Yoshikawa, K. Araki, J. Org. Chem. 2009, 74, 520. 
[22] K. Groom, S. M. S. Hussain, J. Morin, C. Nilewski, T. Rantanen, V. Snieckus, Org. Lett. 2014, 16, 2378.

[23] K. R. Graham, C. Cabanetos, J. P. Jahnke, M. N. Idso, A. E. Laban, G. O. Ngongang Ndjawa, T. Heumueller, K. Vandewal, A. Salleo, B. F. Chmelka, A. Amassian, P. M. Beaujuge, M. D. McGehee, J. Am. Chem. Soc. 2014, 136, 9608.

[24] C. J. Kudla, D. Dolfen, K. J. Schottler, J.-M. Koenen, D. Breusov, S. Allard, U. Scherf, Macromolecules 2010, 43, 7864.

[25] H. Bronstein, R. S. Ashraf, Y. Kim, A. J. P. White, T. Anthopoulos, K. Song, D. James, W. Zhang, I. McCulloch, Macromol. Rapid Commun. 2011, 32, 1664.
[26] D. Baran, M. S. Vezie, N. Gasparini, F. Deledalle, J. Yao, B. C. Schroeder, H. Bronstein, T. Ameri, T. Kirchartz, I. McCulloch, J. Nelson, C. J. Brabec, J. Phys. Chem. C 2015, 119, 19668.

[27] S. Park, J. Cho, M. J. Ko, D. S. Chung, H. J. Son, Macromolecules 2015, 48, 3883.

[28] W. Yue, R. S. Ashraf, C. B. Nielsen, E. Collado-Fregoso, M. R. Niazi, S. A. Yousaf, M. Kirkus, H.-Y. Chen, A. Amassian, J. R. Durrant, I. McCulloch, Adv. Mater. 2015, 27, 4702.

[29] Y. Liu, J. Zhao, Z. Li, C. Mu, W. Ma, H. Hu, K. Jiang, H. Lin, H. Ade, H. Yan, Nat. Commun. 2014, 5, 5293. 